\title{
Differences in Faculty Development Needs: Implications for Educational Peer Review Program Design
}

\author{
Kate E. Toth \\ Colleen A. McKey \\ McMaster University
}

\begin{abstract}
The purpose of faculty development in terms of the educational role is to assist faculty in becoming better educators. Educational peer review (EPR) is one method of faculty development. This article is based on a study that explored the different development needs of nursing faculty within a school of nursing at an Ontario university. The study explored on three variables of interest: level of skill acquisition, type of faculty appointment, and type of teaching. A qualitative research design in the case-study tradition was employed. Findings indicated that faculty challenges could be grouped into three themes: job knowledge, skills development, and systems challenges. Job knowledge and skills development challenges varied by level of skill acquisition and type of teaching, while identified systems challenges were related to type of appointment. A flexible EPR program that allows for some customization may lead to an increased ability to meet individual faculty development needs and greater faculty buy-in.
\end{abstract}

\section{RÉSUMÉ}

Le but du développement de faculté dans le rôle éducatif est d'aider la faculté à devenir des meilleurs éducateurs. L'évaluation éducative par les pairs (EEP) est une méthode de développement de faculté. Cette étude a exploré les différences dans les besoins de développement de faculté d'une faculté d'infirmiers dans une école d'infirmiers à une université d'Ontario basée sur trois variables d'intérêt : niveau d'acquisition de compétence, type de désignation de faculté et type d'enseignement. Un protocole de recherche qualitatif dans la tradition d'étude de cas a été 
utilisé. Les résultats ont indiqué que des défis de faculté pourraient être groupés dans trois thèmes: la connaissance de travail, le développement de compétences et les défis du système. La connaissance de travail et les défis de développement de compétences ont varié par le niveau de l'acquisition de compétence et le type d'enseignement, alors que des défis du système identifiés étaient liés au type de désignation. Un programme flexible de EEP, qui tient compte de personnalisation, peut mener à la capacité accrue de répondre aux différents besoins de développement de faculté et au plus d'acceptation de faculté.

\section{INTRODUCTION}

Viewing teaching as an aspect of the faculty role that is worthy of scholarship is essential to evidence-based educational practice (Emerson \& Records, 2008; Glanville \& Houde, 2004). Clearly, the educational role encompasses more than time spent at the front of a classroom; curriculum development and revision, educational administration roles, student advising, planning programs of study, and creating environments conducive to learning are also essential functions (Emerson \& Records, 2008). Emerson and Records (2008) noted that although performing these functions is necessary, it is insufficient for building the scientific knowledge base for evidence-informed educational practice: "That challenge requires the application of the scientific process, which involves curiosity about what works and what does not, rigorous examination through both quantitative and qualitative approaches, peer review of the results, and their public dissemination" (p. 359).

Education in a practice discipline adds considerable complexity to the role. Practice disciplines, particularly those in the health sciences, often require faculty to maintain a clinical practice role in addition to education, scholarship, and service expectations (Smesny et al., 2007). In nursing, knowledge and theory must be integrated in the practice environment, where nursing has an impact on the health of individuals and populations. Testing the effectiveness of the transmission of knowledge is critical to achieving the educational mandates of practice disciplines (Emerson \& Records, 2008). Robinson (2009) noted that the traditional teaching strategy, which involves passive transmission of information from faculty to learners, will be insufficient to prepare the future nursing workforce.

Professional development is key to the improvement of faculty skills. Broadly defined, faculty development is any type of activity that is aimed at renewing or assisting faculty in their roles (Steinert, 2000). For the purposes of this article, faculty development is considered specifically in its role of helping faculty to improve both their teaching skills and student learning outcomes. Educational peer review (EPR) is regarded as a concrete example of faculty development in the educational role; it can be defined as any interaction in which faculty engage in scholarly discussion about education, rather than being limited to a judgment of others' performance (Quinlan \& Åkerlind, 2000). EPR is valuable for several 
reasons. Hutchings (1996b), for example, argued that the peer review of teaching not only leads to the sharing of best practices but also ensures the enhancement of teaching is under the purview of teaching professionals, recognizes the difficulty of learning the art and science of teaching on one's own, and acts as a complementary source of performance data to student evaluations.

Most of the literature on EPR consists of narrative cases in which anecdotal evidence of what a single department has designed and implemented is provided as a guide for other organizations. Particularly in larger departments, differences in faculty needs - based on a number of variables such as number of years of experience in teaching - are likely, yet a one-size-fits-all approach to EPR appears to be the norm. Thus, it would seem worthwhile to explore whether such variables impact the challenges experienced by faculty in their educational roles and whether these challenges could be better addressed by an approach to EPR that does not place all faculty members in the same mould.

This article focuses on one aspect of a larger study on educational leadership and EPR within a school of nursing at an Ontario university. The goal of the larger study was to inform the design, development, and implementation of an EPR program in the study site. The aspect of the study described here explored differences in faculty development needs, based on three variables: level of skill acquisition, type of faculty appointment, and type of teaching.

The theoretical framework used for level of skill acquisition was that of Benner (2001). Benner emphasized that skill acquisition occurs through the application of theory to real-world situations and that expertise is acquired only through experience. Benner's work on excellence in clinical nursing practice is based on the Dreyfus model. According to this model, learners move through five stages of skill acquisition: novice, advanced beginner, competent, proficient, and expert (pp. 20-36). Although Benner's use of the model was in a clinical setting, it may provide an example of how nurse educators attain professional excellence.

Background on faculty development, the scholarship of teaching, and EPR in the literature are provided next, followed by three examples of the one-sizefits-all approach. The findings of the present study are then discussed to illustrate why this approach may not be the best option for departments considering implementation of EPR as a means of faculty development. These findings are discussed in relation to the literature, and suggestions are made for practical application and future research.

\section{BACKGROUND}

\section{Faculty Development and the Scholarship of Teaching}

Faculty development in the educational role and the scholarship of teaching should be closely linked. The discussion of teaching as scholarship began with Boyer (1990), who argued that research had been too narrowly defined as the discovery of new knowledge and that a broader definition of scholarship 
would help to diminish the role conflict between teaching and research experienced by faculty. He contended that the faculty role involved four separate but interrelated scholarly functions, namely, the scholarship of discovery, the scholarship of integration, the scholarship of application, and the scholarship of teaching (p. 16).

Glanville and Houde (2004) noted that Boyer's definition of the scholarship of teaching was vague and that he did not draw a clear line between scholarly teaching and the scholarship of teaching and learning (SOTL). Martin (2007), in her review of the literature, identified three key differences between these two concepts. The first concerned focus, that is, scholarly teaching is focused on effective teaching, while SOTL focuses on student learning. The second was evidence, that is, evidence of scholarly teaching includes contributions to curriculum development, student ratings, peer review, and teaching portfolios; in contrast, evidence of SOTL is much more public, including many of the traditional methods of demonstrating scholarship (e.g., papers, presentations). The third difference involved evaluation, that is, while the evaluation of scholarly teaching is largely private through reflection on feedback, SOTL by its very nature requires evaluation to be made public and, thus, it occurs in the public domain as do the traditional notions of scholarship. Indeed, as McKinney (2007) noted, SOTL is meant to inform the practice of many.

Glassick, Huber, and Maeroff (1997) argued that the scholarship of teaching is not valued to the same extent as the more traditional scholarship of discovery because it is more difficult to evaluate. Ramsden and Martin (1996) asserted that the recognition of teaching requires better methods of evaluating teaching performance, institutional support and leadership, and quality management strategies that are linked to processes for recognizing teaching. Methods of determining quality in research (e.g., peer review) can be adapted to the assessment of educational performance (Glassick et al., 1997). In effect, peer review is considered essential to a definition of scholarship, regardless of the nature of the piece of work (Martin, 2007; Smesny et al., 2007).

\section{Educational Peer Review}

Two significant educational peer review (EPR) initiatives have taken place in the Western hemisphere in recent years. The first was an initiative of the American Association for Higher Education (AAHE) in the mid-1990s (Hutchings, 1996a). This project, which involved 36 participating departments in 12 U.S. universities, used a wide variety of peer-collaboration approaches. The second major initiative occurred in the United Kingdom, beginning in 2002 (Lomas \& Nicholls, 2005). The Higher Education Funding Council's 2003-2008 strategic plan included a goal to promote the value of excellence in teaching to the same (high) degree as that of research; to this end, the Quality Assurance Agency for Higher Education conducted institutional audits on teaching and learning quality. However, although these two initiatives provided a useful body of literature on implementing EPR within higher education, they were each a further illustration of the one-size-fits-all approach to EPR. 
Quinlan and Åkerlind (2000) conducted a comparative case study on EPR projects in two departments within the AAHE initiative, with the intent of examining the impact of academic culture on successful implementation. The projects chosen by each department were considerably different in purpose and content. One of the departments implemented teaching circles, which were opportunities for faculty members to voluntarily meet to discuss issues related to teaching (such as race, gender, classroom climate, and the use of graduate teaching assistants in large classes). The other department implemented a course review in which seven volunteer faculty members identified elements and examples of good teaching and student learning. Although the context of the department was considered in each case (e.g., voluntary teaching circles for professional development purposes were chosen to ensure that the EPR project was not seen to be evaluative or punitive by a faculty suspicious of administration), a needs assessment to examine what would meet the needs of all faculty members does not appear to have been carried out. In the case of the teaching circles, the participation rate was 50\%, suggesting that this initiative did not meet the needs of all faculty members.

Hutchings (1996a) compiled an extensive number of faculty reports as part of the AAHE's EPR initiative. The projects that were implemented ranged from classroom visits to student interviews to mentorship programs to teaching portfolios. For example, Dunbar (1999) described his math department's implementation of team meetings on a newly revised calculus course. All of the faculty members involved in teaching this course voluntarily participated in weekly meetings to discuss what was and was not working in the classroom. Dunbar noted that the success of this initiative led to a culture of a "more consultative, collective model of course delivery" (p. 62).

Lomas and Nicholls (2005) conducted a case study in which one peer review model was implemented across an entire large university. The initiative required mandatory participation but was developmental in focus and involved each lecturer being observed in the classroom once a year. Pre-observation and post-observation meetings were conducted for discussion purposes between the reviewer and the faculty member under review. An anonymous summary sheet was sent to the department's administration office to share good practices and identify faculty development needs. Lomas and Nicholls indicated that most faculty members embraced EPR and found it valuable, although a small minority was openly hostile to it.

In summary, the literature on EPR has focused on the implementation of one-size-fits-all programs within departments or the university as a whole. The present study sought to explore a potential gap in the literature regarding differences in faculty development needs for nurse educators.

\section{METHOD}

A qualitative research design in the case-study tradition was employed, an approach that was inextricably linked with the study's setting in the School 
of Nursing. In order to help the School design a successful EPR initiative, the data had to reflect the needs, perspectives, and meanings that were specific to the site and the people involved.

\section{Data Collection}

To develop a full understanding of the context of the case, data were collected through an exploration of archival records and documentation related to EPR. In-depth, semi-structured interviews were conducted with the 17 study participants; sampling occurred until data saturation was reached. The interview guide included questions such as: If you were designing an EPR program for the department, what would it look like? How would you define "peer"? What type of process would you put into place? What types of activities would be useful for EPR? In addition, an online forum was developed to allow participants to continue to interact with the study, through member checking, data analysis, and data interpretation.

\section{Data Analysis and Interpretation}

Data analysis was conducted with the aid of NVivo 7 computer software (QSR International, 2007). The methods outlined by Miles and Huberman (1994) were employed, beginning with data reduction through contact summary sheets following each participant contact. Interviews were recorded and transcribed before being imported into NVivo for analysis. Descriptive and pattern coding were utilized, and data analysis was supported by the use of data displays (matrices and network maps). Data interpretation employed three strategies discussed by LeCompte and Schensul (1999): speculating with research partners (through the online forum); reviewing research questions to ensure that each was addressed by the data collected; and developing recommendations for the program. To enhance trustworthiness, data triangulation and member checking were employed (Lincoln \& Guba, 1985).

\section{CONTEXT OF THE CASE}

The relevant population included all faculty members associated with the study site. Within this population, there were three categories of faculty: full-time, part-time, and clinical. Full-time faculty members depend upon the School of Nursing for their primary source of income, and their role encompasses responsibilities for education, research, clinical service, and/or administration in varying degrees. Part-time faculty may or may not hold an official academic appointment with the University, but they are paid for their contributions to education. Clinical faculty members hold unpaid academic appointments with the University; they donate a minimum number of hours to the School while they are employed with hospitals and community agencies across the province. The School's undergraduate program focuses on two aspects of teaching: classroom teaching in small groups, following the problem-based learning (PBL) approach; and supervised clinical practice in a health-care setting. 


\section{Selection of Participants}

A maximum variation sampling strategy (Merriam, 1998) was employed to sample faculty at different levels of skill acquisition, different types of appointments, and both types of teaching. The faculty members who participated in the study were volunteers. An open call for participants was extended via email to all faculty associated with the School of Nursing. Those who responded to the invitation to participate were emailed a demographics questionnaire, which asked them to self-identify their level of skill acquisition, according to Benner's (2001) framework, and their type of teaching. Since participants could be at different levels of skill acquisition in different types of teaching, more than one level could be selected. Informed consent was also obtained at this time. Responses to the questionnaire were reviewed to ensure that the sample reflected the desired diversity in the variables of interest.

\section{Description of Participants}

Of the 17 faculty members in the School of Nursing who were selected to participate in the study, 6 were full-time faculty, 6 were part-time faculty, and 5 were clinical faculty. More of these participants represented the proficient and expert levels of skill acquisition than the other levels. Most (65\%) taught in both theoretical and clinical courses and therefore could be represented in more than one level of skill acquisition.

The participants were mostly female (82\%), the majority (93\%) of them nurses who had been practising for 15 or more years. In terms of length of affiliation with the School of Nursing, 53\% of participants had been with the School for fewer than 5 years, and $47 \%$ had been there 6 years or longer. The participants with fewer than 2 years' affiliation were all part-time or clinical faculty, while those with more than 15 years' affiliation were all full-time faculty. Given the recruitment and retention patterns in these different faculty categories, these findings were not surprising. Length of involvement with nursing education (whether at the study site or elsewhere) was also almost evenly split between those with 5 or fewer years of experience (47\%) and those with 6 or more years (53\%).

\section{FINDINGS}

Participants were asked about their greatest challenges as educators and the areas they had identified for professional growth in their educational role. Since these two questions tended to elicit similar responses, they were analyzed together. Three themes were found in the data: job knowledge, skills development, and systems challenges.

Job Knowledge

Faculty participants identified three key areas in which they wanted to im- 
prove their own knowledge: a greater understanding of the literature; keeping current with health care and education trends; and learning about pedagogy. A part-time, competent faculty participant commented:

At this point, I think my greatest challenge is in that theoretical application. In my previous position teaching, there was nothing. There was no curriculum base; we just started from scratch. They wanted to get that program up and running, so we really only had time to ... get the students prepared for those RN exams and we didn't look at how we could do that and what was the best way for us to do that. We kind of used what we were comfortable with and went with that. So learning for me, it's ... doing that theory learning and learning to apply more academic principles.

On the same theme, a part-time, advanced beginner/proficient faculty participant stated:

Some of the courses I do ... it's knowing what the issues of the day are. So keeping current with current events, with health care policy decisions that are going on. With what the Ministry of Health is doing ... And because I'm not out in that world anymore, it's reading the newspapers and reading journal articles and participating in discussions with people who are out there. So I think that's probably my greatest challenge is trying to stay current.

\section{Skills Development}

Several areas of skills development, the second theme, were identified by the study participants, including: greater competency in the problem-based learning approach; helping students understand concepts; balancing challenging students with creating a supportive learning environment; meeting the needs of all students; applying theory to practice and enabling students to see the relevance of theoretical learning; ensuring students learn what they are supposed to learn; fostering critical thinking skills; and improving group facilitation skills.

Two participant comments on this theme were as follows:

I think my greatest [challenge] is one that I started with and that I still feel like I'm working on and that's really being good at the problem-based learning format. And that's something that it's not a background that I came from. That's not a style I was familiar with when I started working [here], and so it's something that I keep working on - that great way of questioning students and getting them to generate answers and not reverting too much to the lecture style. (Clinical, advanced beginner faculty participant) 
I think fostering critical thinking and problem solving. That's tough because when you're working with novice students, it's really difficult to get them to think through an issue and ... [pause] ... come to a reasonable response. I think there's some things that we can do as educators to assist with that, but I firmly believe as well that some of that, there's no other way to get to that point other than experience and to put in the time, to see a million and a half patients or whatever it takes [laughing]. There's no substitute for that experience. But I would like to know how to do that better. (Clinical, expert faculty participant)

\section{Systems Challenges}

Participants identified four main systems challenges: not being asked to teach enough to be truly comfortable in the teaching role; understanding how one fits within the system of the School of Nursing and its curricula; lack of feedback; and lack of stability in courses being taught and constant tweaking of the curriculum. Examples of comments around this theme included:

You know, I would consider myself still a fairly new faculty member even after it's almost 10 years now, just because I've probably only tutored maybe half a dozen fourth-year students in that time because of the opportunities that have arisen. So I still haven't had experiences with lots of things. (Clinical, advanced beginner/competent faculty participant)

There's one thing that irritated me a lot that hasn't changed and that is that there's constant tweak, tweak, tweak, change, change, change to the curriculum year after year after year. It's little bits at a time ... it looks like it's a small thing, but over a few years it turns out that it's a lot that's changed and I think for educators it's like following a bouncing ball. What exactly [laughing] are the contents of this curriculum? Because we change it every single year in one way or another ... I know we flip people around a lot too and it's very hard to become an expert, a content expert in this program because one year you're teaching these four courses and the next year it's four completely different ones. (Full-time, expert/proficient faculty participant)

These findings demonstrate that there are clear differences in faculty needs based on the three variables of interest, that is, level of skill acquisition, type of faculty appointment, and type of teaching.

\section{Differences Based on Level of Skill Acquisition}

A continuum of learning emerged within the job knowledge theme, with advanced beginner and competent faculty identifying more basic content, such 
as theoretical application and pedagogy, while proficient and expert faculty identified issues such as keeping current with global health care trends and understanding students (generational differences).

In the area of skills development, the same pattern was observed. Faculty members at the advanced beginner level of skill acquisition tended to identify skills such as teaching using the PBL approach and applying theory to practice, while competent faculty spoke about helping students understand concepts and applying theory to practice. Proficient and expert faculty identified several issues: struggling to achieve a balance between challenging students and still creating a supportive learning environment; ensuring that students learn what they should be; fostering critical-thinking skills; and developing and maintaining group facilitation skills. Again, a continuum of more basic to advanced skills could be seen in these responses. Faculty members at all levels of skill acquisition mentioned the challenge of meeting the needs of all students. Systems challenges did not appear to vary based on level of skill acquisition; rather, they were more closely linked to type of faculty appointment.

As Benner's (2001) framework suggested, discernible differences existed in faculty responses based on level of skill acquisition. Faculty members at the higher levels of skill acquisition expressed greater confidence in their own knowledge and abilities, more comfort with lack of structure, and greater difficulty with identifying challenges. When they did identify challenges, those challenges tended to be more complex and at a systems level.

\section{Differences Based on Type of Faculty Appointment}

Study participants expressed some explicit differences in job knowledge requirements based on type of faculty appointment. Not surprisingly, those in the part-time and clinical categories emphasized a desire to increase their knowledge of the literature and pedagogy. This makes sense since full-time faculty participants were more likely to be $\mathrm{PhD}$-prepared (and thus often exposed to pedagogical theory and the literature through their education) and more immersed in the academic culture as a product of their full-time faculty status.

Full-time and part-time faculty identified job knowledge requirements as understanding students and keeping current. It may be that full-time and parttime faculty taught on a regular basis and so were more exposed to the differences in generations. As for keeping current, clinical faculty members were more likely to be employed in a clinical setting and thus less likely to feel as removed from that setting as those who worked specifically in the academic sector.

Clinical faculty participants identified most of the systems challenges. These challenges included: irregular teaching; balancing workload between volunteer teaching and full-time paid positions elsewhere; understanding how they fit within the system; and lack of feedback. Due to the nature of their role, clinical faculty tended to feel more isolated and less connected to the School of Nursing. If they taught strictly in the clinical setting, they may never have set foot inside the University. This situation poses significant challenges to the School 
in terms of building a sense of community, ensuring faculty have the skills they need to deliver the curriculum, and evaluating teaching performance and reappointment and promotion applications.

Several interrelated systems challenges transcended type of faculty appointment. Faculty members discussed the challenges of not teaching the same courses consistently, as this meant they were continually learning new courses. At the same time, they spoke about the curriculum constantly being tweaked and the challenges that posed to improving their proficiency with the course content. The end result, they felt, was a lack of consistency, which was identified as one of the overarching themes in the data. Indeed, in the larger study, both faculty and administration participants specified improved consistency as a key potential benefit of EPR.

\section{Differences Based on Type of Teaching}

The majority of faculty who participated in this study taught both theoretical and clinical courses. Five faculty members taught theoretical courses only, and one taught clinical courses only. In terms of job knowledge, type of teaching did not appear to significantly influence the themes that were identified, with one exception: pedagogical knowledge tended to be mentioned by those teaching solely in the theoretical setting. It may be that those teaching clinical courses rather emphasized the imparting of clinical knowledge than the educational principles applied. However, given that this theme also tended to be mentioned most frequently by less-experienced faculty, it may be more closely related to level of skill acquisition than to type of teaching.

In the area of skills development, some clear patterns emerged by type of teaching. Those teaching theoretical courses mentioned the use of the PBL (problem-based learning) approach, which is used only in theoretical courses, as well as helping students understand concepts and group facilitation skills. These patterns are necessarily more important in theoretical courses because in two cases (PBL and group facilitation), they occurred more frequently in that setting, while in the case of helping students to understand concepts, the clinical setting tended to focus more on applying concepts. Thus, understanding is necessary before the next step can be taken to application. Faculty who taught in both types of courses identified skills in meeting the needs of all students, applying theory to practice, and fostering critical thinking skills.

Systems challenges did not seem to vary based on type of teaching performed, although they did vary by type of faculty appointment. It may be that systems challenges transcended type of teaching or the sample made differences in this area difficult to detect.

\section{Educational Peer Review Activities}

In defining EPR, faculty participants felt strongly that the concept should encompass the entire educational role, not simply teaching in the classroom 
or the clinical setting. When asked about potentially useful activities for EPR, faculty members had numerous suggestions. Most endorsed direct observation in the classroom or clinical setting. In fact, some faculty felt that direct observation was mandatory, while other activities could be added to further supplement the data on the individual's fulfillment of the educational role. The following excerpt best illustrates this point:

There's direct observation, which I think is critical in our program because of the way we deliver the curriculum. It's highly resource-intensive; it's highly student and teacher engaged. So I think direct observation is really, really an essential.

Several other EPR activities were identified by participants: the opportunity to dialogue with peers in an informal or formal setting (activities noted under this category ranged from informal sharing of challenges to formal interviews to discussing teaching and other educational roles); review of marking and commentary on student assignments; videotaping as an alternative to direct observation; discussion of class preparation; review of grades and student ratings; review of work on research projects or committee participation; course meetings; feedback on tools or resources developed by the faculty member, including work on curriculum; and student interviews. This diverse range of activities could provide a wealth of data on the fulfillment of each faculty member's whole educational role.

\section{DISCUSSION}

This study sought to identify how faculty professional development needs might differ based on three specific demographic variables of interest: level of skill acquisition, type of faculty appointment, and type of teaching. As illustrated in the findings, differences existed between faculty participants for each of these variables. One of the essential purposes of EPR is to meet the professional-development needs of faculty in their educational roles. Given the significant differences in educational challenges experienced by the study participants, a one-dimensional approach to EPR may not address the needs of all faculty members.

Participants were asked to name activities that might be useful for EPR, and 10 distinct activities were acknowledged. If the model used in the literature on EPR were to be applied to this study setting, the department would choose one of these distinct activities and implement it for all faculty members. Direct observation would likely be chosen as the activity most frequently identified, and the result would be similar to the study discussed by Lomas and Nicholls (2005). Although this would undoubtedly provide rich data on faculty members' classroom instruction, considerable other data related to professional development and performance would remain unseen. For example, a review of marking and feedback provided to students on written assignments would provide information on another vital aspect of the educational role. Theoretically, a 
faculty member could be a wonderful facilitator of class discussions using the PBL approach but provide negligible feedback on written assignments, leaving the students unable to improve. In fact, Cohen (2003) cautioned that "classroom performance is not the same as teaching excellence" (p. 2), warning against what he termed "drive-by assessments."

The environment of this study site is different from many academic departments outside of nursing, in that a single faculty member is not usually responsible for the development, design, and delivery of a course (although this does sometimes occur in the graduate or specialty education programs). Instead, multiple faculty deliver the same undergraduate curriculum in smallclass sections. Thus, some EPR activities commonly cited in the literature, such as exchange of syllabi, do not necessarily apply to this setting. In contrast, the School's environment does offer some unique opportunities for EPR, such as team teaching.

\section{Limitations}

Two limitations of this study are important to note. First, participants selfidentified their level of skill acquisition. Thus, it is possible that these faculty participants self-selected a higher level of skill acquisition than they actually possessed for reasons of social desirability. This may have impacted the findings, specifically around the continuum of faculty development needs related to EPR. Second, there were small numbers of participants in some variable categories. This aspect made it difficult to conduct a true analysis of differences in these categories. Future research should further investigate these issues with larger numbers of participants.

\section{Recommendations}

The findings of this study support the notion that faculty members may have diverse professional development needs based on a number of variables. This has implications for the design of EPR and other faculty development programs.

First, we recommend that departments identify the different types of faculty employed within the department and consider these variables during program design. A needs assessment can be very helpful in making informed design decisions.

Second, we recommend that programs provide flexibility and customizability where feasible. This may add to program complexity (and therefore required resources); however, benefits to faculty, students, and the department as a whole may justify the investment. Participants in this study felt that a guiding framework for EPR was important, but they also emphasized the value of a process in which some customization to individual needs was possible.

Third, the findings suggest that it is important to consider the entire educational role in designing faculty development programs. Several EPR activities were identified that would allow for professional development throughout the scope of the role, instead of teaching alone. Furthermore, the literature supports 
a wide variety of EPR options. A flexible EPR program that provides a range of options for faculty is likely to be successful in meeting individual needs.

Finally, we recommend that faculty be heavily involved in program design. Active faculty participation in the process and outcome may increase faculty buy-in, which is critical for program success (Bernstein, 1996; Brown \& WardGriffin, 1994).

\section{CONCLUSION}

The study discussed in this article contributes to the literature through its identification and exploration of a potential gap in the EPR literature. The findings suggest that the identified gap is legitimate; however, at the present time, no evidence exists to confirm that the type of program proposed here will serve to better meet faculty development needs. Future research should investigate the advantages and disadvantages of customizable EPR programs, particularly as they pertain to meeting the professional development needs of faculty.

\section{REFERENCES}

Benner, P. (2001). From novice to expert: Excellence and power in clinical nursing practice (Comm. ed.). Upper Saddle River, NJ: Prentice Hall Health.

Bernstein, D. J. (1996). A departmental system for balancing the development and evaluation of college teaching: A commentary on Cavanagh. Innovative Higher Education, 20(4), 241-247.

Boyer, E. L. (1990). Scholarship reconsidered: Priorities of the professoriate. New York: The Carnegie Foundation for the Advancement of Teaching.

Brown, B., \& Ward-Griffin, C. (1994). The use of peer evaluation in promoting nursing faculty teaching effectiveness: A review of the literature. Nurse Education Today, 14(4), 299-305.

Cohen, J. (2003). Documenting teaching excellence within the peer review of teaching. Journalism \& Mass Communication Editor, Summer, 1-4.

Dunbar, S. (1999). Faculty report: Developing a course portfolio in math. A report from the University of Nebraska-Lincoln. In P. Hutchings (Ed.), Making teaching community property: A menu for peer collaboration and peer review (pp. 56-58). Washington, DC: American Association for Higher Education.

Emerson, R. J., \& Records, K. (2008). Today's challenge, tomorrow's excellence: The practice of evidence-based education. Journal of Nursing Education, 47(8), 359-370.

Glanville, I., \& Houde, S. (2004). The scholarship of teaching: Implications for nursing faculty. Journal of Professional Nursing, 20(1), 7-14.

Glassick, C. E., Huber, M. T., \& Maeroff, G. I. (1997). Scholarship assessed: Evaluation of the professoriate. San Francisco: Jossey-Bass. 
Hutchings, P. (Ed.). (1996a). Making teaching community property: A menu for peer collaboration and peer review. Washington, DC: American Association for Higher Education.

Hutchings, P. (1996b). The peer review of teaching: Progress, issues and prospects. Innovative Higher Education, 20(4), 221-234.

LeCompte, M. D., \& Schensul, J. J. (1999). Analyzing and interpreting ethnographic data. Walnut Creek, CA: AltaMira.

Lincoln, Y. S., \& Guba, E. G. (1985). Naturalistic inquiry. Newbury Park, CA: Sage.

Lomas, L., \& Nicholls, G. (2005). Enhancing teaching quality through peer review of teaching. Quality in Higher Education, 11(2), 137-149.

Martin, L. (2007). Defining the scholarship of teaching versus scholarly teaching. Teaching and Learning in Higher Education, 46(Spring), 1-3.

McKinney, K. (2007). Enhancing learning through the scholarship of teaching and learning: The challenges and joys of juggling. Bolton, MA: Anker.

Merriam, S. B. (1998). Qualitative research and case study applications in education (Rev. ed.). San Francisco: Jossey-Bass.

Miles, M. B., \& Huberman, A. M. (1994). Qualitative data analysis: An expanded sourcebook (2nd ed.). Thousand Oaks, CA: Sage.

QSR International. (2007). NVivo (Version 7) [Computer software]. Melbourne, Australia: Author.

Quinlan, K. M., \& Åkerlind, G. S. (2000). Factors affecting departmental peer collaboration for faculty development: Two cases in context. Higher Education, 40, 23-52.

Ramsden, P., \& Martin, E. (1996). Recognition of good university teaching: Policies from an Australian study. Studies in Higher Education, 21(3), 299315.

Robinson, F. P. (2009). Servant teaching: The power and promise for nursing education. International Journal of Nursing Education Scholarship, 6(1), $1-15$.

Smesny, A. L., Williams, J. S., Brazeau, G. A., Weber, R. J., Matthews, H. W., \& Das, S. K. (2007). Barriers to scholarship in dentistry, medicine, nursing, and pharmacy practice faculty. American Journal of Pharmaceutical Education, 71(5), 1-9.

Steinert, Y. (2000). Faculty development in the new millennium: Key challenges and future directions. Medical Teacher, 22(1), 44-50. 


\section{AUTHOR NOTE}

This article is based on a study conducted for a master's thesis. An earlier version was presented at the 2008 conference of the Canadian Society for the Study of Higher Education (CSSHE). The study was supported in part by grants from the Nursing Education Research Unit (NERU), School of Nursing, McMaster University, and from the School of Nursing, McMaster University. The authors would like to acknowledge the input of Dr. J. Etchegaray and Dr. R. Neswald-Potter, Walden University, Minneapolis, Minnesota, and those who kindly volunteered to participate in the study.

\section{CONTACT INFORMATION}

Kate E. Toth

School of Nursing

McMaster University

Hamilton, ON

L8N 3 Z5

ktoth@mcmaster.ca

Kate Toth is the human resources coordinator for the School of Nursing at McMaster University. A Certified Human Resources Professional with the Human Resources Professionals Association (HRPA), she is currently pursuing a $\mathrm{PhD}$ in Health Psychology. She teaches an undergraduate course in research methods and critical appraisal and supervises students participating in a research practicum.

Colleen A. McKey is an associate professor in McMaster University's School of Nursing. She is a Certified Health Executive with the Canadian College of Health Service Executives and a Fellow in the American College of Health Executives. In addition to serving on national boards and task forces, she is the inaugural assistant dean, Academic Resources, of the School of Nursing and the director of the Leadership and Management Program. She teaches leadership in the undergraduate and graduate programs; her research interests are in leadership and health care. 